\title{
A global perspective on inflation and propagation channels
}

\author{
Luca Gattini ${ }^{1}$ \\ European Investment Bank, Luxembourg \\ l.gattini@eib.org \\ Huw Pill \\ Goldman Sachs, United Kingdom \\ huw.pill@gs.com \\ Ludger Schuknecht \\ Bundesministerium Finanz, Germany \\ ludger.schuknecht@bmf.bund.de
}

\begin{abstract}
This paper revisits the evidence on monetary policy transmission. It extends the existing literature in three dimensions. First, we attempt to internalise potential international channels of transmission by taking a global perspective. More specifically, we explore global aggregates covering a broader set of countries (ca. 70\% per cent of the world economy) and a longer time span (from 1960 to 2013) than previous studies. Second, we broaden the set of transmission channels considered, notably by exploring interactions among monetary variables, inflation and asset prices (including residential property prices). Third, we look at the potential role of public debt in driving price developments, on the grounds underpinned by fiscal theories of the price level. On the basis of a VAR analysis, we find that: (1) global money demand shocks affect global inflation and global commodity prices (which, in turn, impact on inflation); (2) global asset price dynamics respond to financing cost shocks and (very modestly) to shocks to global money demand; and (3) positive house price shocks exert a significant influence on inflation. From a global perspective, the study suggests that an understanding of inflation requires recognition of the externalities that global commodity and asset price developments exert over domestic inflation.
\end{abstract}

JEL classification: E31, E51, E62, C32, F42

Keywords: VAR, global inflation, global house prices, global money 


\section{INTRODUCTION ${ }^{2}$}

The low frequency, reduced-form relationship between monetary growth and inflation is one of the best-established correlations in empirical macroeconomics. However, characterising the structural nature of this relationship - the transmission mechanism by which monetary expansions influence price developments - remains a source of vigorous, ongoing debate.

Recently, Sousa and Zaghini (2007) and Belke et al. (2010a; 2010b) investigated specific structural characterisations of the relationship between monetary variables and inflation developments in global models. Our paper also takes a global perspective, but encompasses previous studies by analysing a wider set of macroeconomic variables, enlarging the geographical coverage of countries, and extending the time period analysed. We construct new global macroeconomic variables according to a 'representativeness' rule, which ensures that coverage meets a minimum threshold on the geographic dimension. In so doing, we ensure our data set incorporates emerging market economies, and thus better captures the new global economy.

Aside from greater geographical and temporal coverage, this paper extends the literature in other dimensions, notably by entertaining three additional potential transmission channels of monetary policy: (1) via international interactions in an increasingly globalised economy, notably through the evolution of commodity prices; (2) via interactions between monetary variables (liquidity and interest rates) and asset prices (specifically residential property prices), a relationship that has achieved growing interest in the literature; and (3) via interactions with balance sheet variables, in particular the stock of public debt and credit to the private sector. From a European perspective, the influence of public debt may be of particular interest, given the Euro area fiscal and sovereign crisis that started in late 2009.

Our analysis covers a time period spanning 1960 to 2013 and employs eight quarterly time series: money, credit to the private sector, real GDP, the consumer price index, house prices, the stock of public debt, the level of short-term interest rates and global commodity prices. The country coverage in each period $t$ represents at least 68 per cent of world GDP measured in terms of Purchasing Power Parity (PPP).

Having established the statistical properties of our time series, we employ a vectorautoregression (VAR) approach to explore interactions among the variables and the relative importance of various possible propagation channels. Starting from a benchmark structural characterisation similar to previous studies (embodying short-term interest rates, inflation, GDP, money and commodity prices), we augment our VAR model by adding house prices, private credit and public debt. Finally, we conduct a set of robustness checks.

To anticipate our conclusions, we establish the following results.

First, global monetary shocks affect both global inflation and global commodity prices. In turn, global commodity price shocks affect global inflation. These findings highlight an additional global transmission mechanism via commodity prices to global inflation. Inflation in individual countries will be influenced by global commodity price dynamics that are likely to be beyond the control of domestic monetary authorities.

Second, at the global level asset/property price dynamics appear to be driven primarily by financing cost shocks, rather than being driven by shocks to global money. Moreover, an increase in house prices exerts a positive influence on global inflation.

Third, there appears to be a modest, but negative, relationship between public debt and inflation. One interpretation of this empirical relationship is that it reflects Ricardian effects, where higher public debt weighs on private demand, thus reducing inflation. While looking

\footnotetext{
We are grateful for the helpful comments of Antonello D’Agostino, Andreas Beyer, Björn Fischer, Julian von Landesberger, Philippine CourThimann and Oskar Nelvin, as well as the suggestions of an anonymous referee. Moreover, we also thank the participants in the ECB seminar on inflation transmission channels. The views expressed in this paper are those of the authors and do not necessarily reflect the views of the ECB or those institutions with which they are currently affiliated.
} 
forward one might entertain a positive link between public debt and global inflation stemming from concerns about potential fiscal dominance over the price level (Sims, 1994) and given the substantially higher level of global public indebtedness after the financial crisis, there is little evidence of such an interaction in our data set.

The remainder of our paper is organised as follows. After reviewing the literature in Section 2, we outline the construction of the data and summarise its time series properties in Section 3 . Section 4 describes our empirical analysis, including the methodology employed, and presents the results and robustness checks. Section 5 concludes.

\section{LITERATURE REVIEW}

Many previous studies have explored the relationship between monetary growth and inflation. In a seminal article, Lucas (1980) applies statistical filters to characterise the relationship between M1 and consumer prices in U.S. data. He finds that the relationship becomes more regular, with a coefficient closer to one, as the filtering process focuses on the low frequencies in the two time series (i.e. the long-run relationship). Lucas (1980, p. 1005) claims that the low-frequency relationship he finds represents "one way in which the quantity-theoretic relationships can be uncovered via a-theoretical methods from time-series which are subject to a variety of other forces."

McCandless and Weber (2005) found a high (almost unit) correlation between the rate of monetary growth and the rate of inflation in a cross-country panel. This result is robust across different definitions of money and across various sub-samples of countries. Benati (2009) has shown that, over the last two centuries, the fraction of long-run variation in inflation explained by long-run money growth has been very high and relatively stable. Moreover, he sheds light on the unit relation associated with the quantity theory of money. He shows that infrequent but significant inflationary bursts underpin the one-for-one correlation between money growth and inflation.

Over the past decade, the global dimension of the money-inflation relationship has received increasing attention. From a forecasting perspective, Ciccarelli and Mojon (2010) offer evidence that a common international component accounts for 70 per cent of the variance in domestic inflation in industrialized economies. D'Agostino and Surico (2009) stress that global liquidity produces forecasts of US inflation that are significantly more accurate than the forecasts based on US money growth and country-specific components alone. Such analyses build on the insight of McKinnon (1984), offered more than a quarter of a century ago.

With these stylised facts in mind, a growing number of studies have analysed potential transmission channels from money to global inflation via vector autoregression models, in both reduced form (VAR) and structural form (SVAR), with aggregated global data.

Sousa and Zaghini (2007) constructed a global aggregate for the G5 economies with a starting date in the early 1980s and apply a SVAR approach to the data. They find that prices respond significantly and positively to global liquidity shocks. Their result is robust to various compositions of the aggregate. Consequently, they argue that cross-country monetary flows - e.g., capital flows - may make it more difficult to disentangle the relation between money, inflation and output at the regional or national level. Rueffer and Stracca (2007) analysed a similar group of countries over the sample 1980-2004 and used a similar set of variables. They found support for the conjecture that monetary aggregates may convey some useful information on variables that matter for inflation, concluding that liquidity is a useful indicator of inflationary pressures at the global level. They also studied the impact of global phenomena on domestic variables. In this case, they found that the channels through which liquidity can be transmitted cross-borders are more elusive and ambiguous. Additionally they also augmented the global model with property 
and equity prices and they did not find significant evidence of excess liquidity impacting on asset values at a global level.

Belke et al. (2010a) expand on this previous literature. They constructed aggregate time series for the major OECD economies and, by the means of a cointegrated VAR, showed that the inclusion of commodity prices helps to identify a relevant transmission mechanism from global liquidity to other macroeconomic variables. In other words, global liquidity contains important information for the evolution of commodity prices, which in turn are an important driver of aggregate demand and inflation. This supports the view that commodity movements are, to some extent, an outcome of a monetary phenomenon, with causality running from monetary variables to commodity prices. Belke et al. (2010b) develop this analysis by introducing house prices in place of commodity prices and find a significant response of house prices to global liquidity (in contrast with Ruffer and Stracca (2007)). They also find a significant and positive relationship between global and regional liquidity (either credit or money), on the one hand, and country specific developments of asset prices, on the other, corroborating the work of Alessi and Detken (2009) and Agnello and Schuknecht (2009). Interestingly, Belke et al. (2010b) also find subsequent spillovers from asset prices to consumer prices at the global level. Moreover, they find a positive impact of house prices on global liquidity, which is interpreted as an effect of increased demand for credit. Accordingly they find house prices are an important component of global inflation dynamics and this of their model.

As regards monetary and fiscal policy interactions, the potential effects of public debt on inflation have not been studied at the global level thus far. In general, the so-called fiscal theory of the price level is based on fiscal and monetary policy rules such that the price level is determined by government debt and fiscal policy alone, rather than by monetary policy settings. In a theoretical framework, Sims (1994) stresses that in a fiat-money economy, the value of fiat money depends on public beliefs about fiscal policy under circumstances that are never observed in equilibrium: in this context, inflation is a fiscal phenomenon. Little empirical evidence has looked into the usefulness of a fiscal rule in accounting for the evolution of prices. Empirical analysis conducted in Canzonieri et al. (2001) support the evidence of Ricardian regimes. This in turn suggests that prices are determined in a conventional way, say by money supply and demand. Public debt could then have an inflation increasing effect indirectly via more aggregate demand.

\section{DATA}

\subsection{Time series construction}

Our analysis covers the period spanning 1960 to 2010. We employ eight time series, each with quarterly frequency. Seven of these eight variables are constructed by aggregating national data: money (M), credit to the private sector (CRP), real GDP (Y), the consumer price index (CPI), house prices (RPP), the stock of public debt (D) and the level of short-term interest rates (INT). We also use a global commodity price index (COM), which has been constructed by The Economist newspaper.

Two selection criteria have been applied to the aggregating algorithm. First, a country $i$ is included at time $t$ when the eight series jointly are available at time $t$ for that country $i$. This necessary condition facilitates the comparison across the aggregated variable since the same basket of countries is considered in each period $t$. Second, the country coverage in each period $t$ represents at least 68 per cent of world GDP measured in terms of Purchasing Power Parity (PPPs) and an overall average coverage of at least 70 per cent up to period $t$. 
The PPPs and current GDP levels are taken from the Penn World Table Version 8.0. ${ }^{3}$ This information is used to construct the country weights applied in the aggregation procedure. To obtain global aggregated time series, we follow a similar approach to Belke et al. (2010) (itself based on Beyer et al. (2001)). For a detailed description of the aggregation procedure and the weights employed, refer to Annex A.

Table 1 reports the detailed country coverage and representativeness of the aggregated series. The initial coverage in 1960 included seven economies that accounted for more than 70 per cent of world GDP. The table lists countries depending on the year of entry into the time series. The full coverage incorporates twenty-eight countries. ${ }^{4}$ Since the necessary condition previously described holds at that time only and, more generally, the main constraint in the aggregation is the availability of a house price index, countries enter the aggregate at different times (and some re-enter).

Table 1

Country coverage and GDP-PPPs weight in the world economy

\begin{tabular}{llc}
\hline \hline Year & \multicolumn{1}{c}{ Country coverage } & \% of world GDP-PPPs \\
\hline 1960 & $\begin{array}{l}\text { Australia, Canada, France, United Kingdom, Japan, Netherlands } \\
\text { and United States }\end{array}$ & 72.3 \\
1962 & Germany & 73.0 \\
1965 & Italy & 72.7 \\
1966 & South Africa & 72.9 \\
1970 & Denmark, Finland, Ireland, New Zealand and Switzerland & 71.4 \\
1971 & Spain & 73.5 \\
1976 & Belgium and Singapore & 71.3 \\
1979 & Norway & 70.9 \\
1980 & Sweden & 71.2 \\
1987 & Austria & 68.8 \\
1988 & Portugal & 69.6 \\
1990 & Korea & 68.4 \\
1993 & Hong Kong & 68.1 \\
1995 & Thailand and Greece & 70.9 \\
1998 & China & 73.0 \\
1999 & Malaysia & 72.3 \\
\hline \hline
\end{tabular}

Source: IMF.

The sources for the entire set of variables are primarily IMF, OECD, ECB, Haver Analytics, the Global Financial Database and The Economist newspaper. (For more details on data sources, see Annex B.) The aggregated series have been seasonally adjusted with X-12 methodology, applying an additive seasonal adjustment. ${ }^{5}$

3 Feenstra, R.C., R. Inklaar and M.P. Timmer (2013). "The next generation of the Penn World Table," available for download at www.ggdc. net/pwt.

4 viz., Australia, Austria, Belgium, Canada, Switzerland, People Republic of China, Denmark, Spain, Finland, France, United Kingdom, Germany, Greece, Honk Kong, Ireland, Italy, Japan, South Korea, Malaysia, Netherlands, Norway, New Zealand, Portugal, Singapore, Sweden, Thailand, United States and South Africa.

5 The estimation results reported in the next section have been cross checked with series non-seasonally adjusted and no significant differences have been detected. 


\subsection{Data inspection}

We investigate the statistical properties of the newly constructed series. An initial inspection of the time series can help to gauge the main cycles and potential co-movements across the variables. Chart 1 reports inflation developments against the other seven variables entering our analysis. All variables are reported as a twelve window moving average of the quarter on quarter growth rates. This is done to smooth out the volatility and still capture the major trends for presentational purposes, whereas in our empirical analysis we employ higher (i.e., quarterly) frequency fluctuations.

\section{Chart 1}

Inflation against the other variables (twelve period moving average of quarter on quarter growth rates)
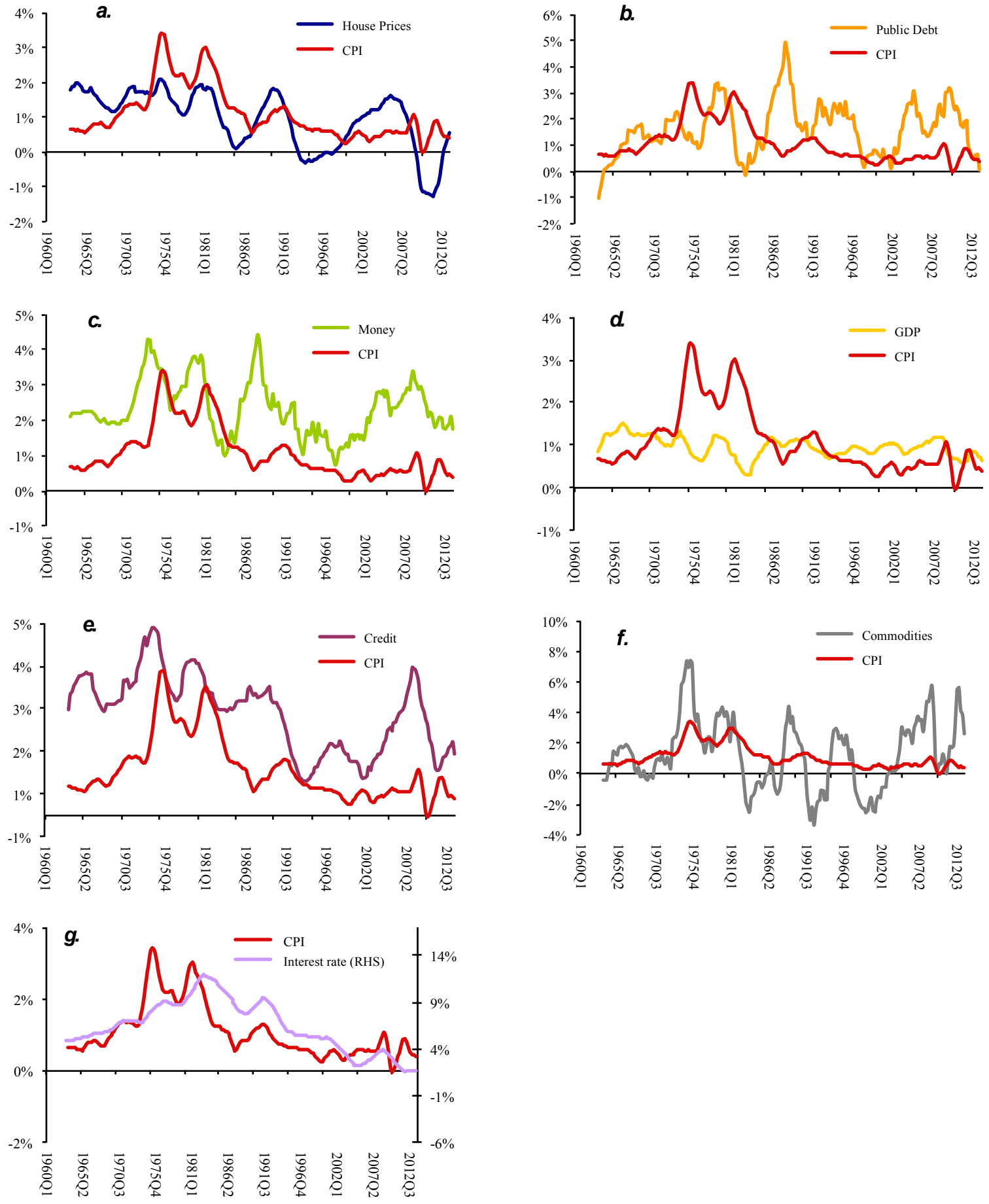

Source: See Annex B. 
Inflation cycles are captured by the CPI variable. The time series pictures the Arab OPEC oil embargo related to the Yom Kippur War of 1973 and the associated spike in oil prices, the oil price increase shocks of 1979-1980 and 1990-1991, and the major oil price decline in 1986. Additionally, it also captures the recent commodity prices surge in the late 2000s. It also represents the great moderation period in inflation dynamics witnessed globally in the last twenty-five years.

Interestingly, the cyclicality in house price dynamics seems to have increased over time. After the mid-1980s house prices show a more exacerbated boom and bust cycle. In other words, a reduction in the volatility of inflation has been coupled with a higher volatility in house price dynamics with a tendency to have more pronounced busts. In the 1990s' cycle and during the current cycle house price growth decelerated sharply and even turned persistently negative.

The moving average of the public debt variable is constructed from the growth rate of the public debt to GDP ratio. It fits the story of increasing deficits and, consequently, overall debt during the recession periods of the 1970s, early 1980s, early 1990s and the 2008-2009 recession. The last cycle stands out for its acceleration in public debt accumulation.

The money variable has been constructed using the broadest available monetary aggregate for every single country in each period. Money and quasi-money comprise of the sum of currency outside of the banks, demand deposits other than those of the central government, savings, and foreign currency deposits of resident sectors other than the central government. M3 has been employed, when available; otherwise M2 or M1 aggregates have been used. It has to be mentioned that the "liquidity spectrum" of such an aggregate may vary across countries. A narrow definition of money, say M1, for country A can be a broad enough definition for country B. For example, short- and medium-term maturity products are more likely to be liquid in mature capital markets where the maturity structure of recipients and payments can be more easily matched. Overall, the employed variables show a lagged, low frequency correlation between inflation cycles and money cycles (Benati, 2009; Pill and Rautanen, 2006).

We have also included an interest rate variable to have a complete coverage of potential monetary channels. Interest rates have been included, following the arguments of Laurent (1988) and Bernanke and Blinder (1992) who stressed that money growth can be influenced by economic conditions. The money growth represents a confluence of both supply factors (monetary policy actions) and demand factors (such as private-sector portfolio shifts). Consequently, the inclusion of interest rates should allow us to capture a further hidden monetary propagation channel.

We have also constructed an aggregated credit to private sector variable, which is defined as claims on private sector (IFS line 32d). It includes gross credit from the financial system to individuals, enterprises, nonfinancial public entities not included under net domestic credit, and financial institutions not included elsewhere. The cyclicality of the credit aggregate is visually correlated with money and it shows more pronounced swings than the monetary aggregate. Additionally, the average growth rate of the private credit variable is higher than the money aggregate. This is also related to the interactions between the money multiplier and banking sector intermediation activity. Last but not least, commodity price dynamics recapitulate the most well-known shocks including the latest commodity cycle as well as a high correlation with inflation cycles characterised by different amplitudes.

Table 2 reports the results of a Granger causality test across all variables. The significant relationships are highlighted in bold. Most, if not all, of the statistically significant results reflect fairly intuitive interactions. 
Table 2

Granger causality test across variables

\begin{tabular}{|c|c|c|c|c|c|c|c|c|}
\hline & CPI & COMMODITY & MONEY & CREDIT & GDP & $\begin{array}{l}\text { HOUSE } \\
\text { PRICES }\end{array}$ & $\begin{array}{l}\text { PUBLIC } \\
\text { DEBT }\end{array}$ & INT \\
\hline CPI & - & 1.63 & 0.35 & 1.43 & $2.60^{* *}$ & $2.27^{* *}$ & $3.17^{*}$ & 1.72 \\
\hline COMMODITY & $4.94^{*}$ & - & $1.99^{* * *}$ & $2.14^{* * *}$ & $2.50^{* *}$ & $5.41^{*}$ & $4.04^{*}$ & $5.11^{*}$ \\
\hline MONEY & $4.00^{*}$ & $2.30^{* *}$ & - & 1.32 & 1.36 & 1.12 & 0.88 & $2.57^{* *}$ \\
\hline CREDIT & $3.27^{*}$ & $2.22^{* *}$ & $3.68^{*}$ & - & $3.47^{*}$ & 1.17 & $1.96^{* * * *}$ & $2.13^{* *}$ \\
\hline GDP & $3.13^{*}$ & $1.92^{* * *}$ & 0.54 & $2.20^{* * *}$ & - & 0.78 & $2.36^{* *}$ & $3.12^{*}$ \\
\hline HOUSE PRICES & $6.06^{*}$ & 1.60 & 1.76 & $2.07^{* * *}$ & $2.49^{* * *}$ & - & $2.55^{* *}$ & $5.43^{*}$ \\
\hline PUBLIC DEBT & $2.82^{* * *}$ & $4.14^{*}$ & 0.69 & 1.66 & 1.64 & 1.01 & - & $3.15^{*}$ \\
\hline INT & 1.29 & 1.70 & 0.47 & 0.76 & $2.52^{* *}$ & $3.25^{*}$ & 1.34 & - \\
\hline
\end{tabular}

F-statistics and ${ }^{*} 1$ per cent, ${ }^{* *} 5$ per cent and ${ }^{* * *} 10$ per cent significance levels.

Note: the Null Hypothesis is, variable Y does not Granger cause variable X'. The test should be read across lines. Hence. any variable on the Y axis does not cause any variable on the $\mathrm{X}$ axis. The test is computed including two lags of the quarterly variables.

Source: Authors' calculations.

All variables Granger cause inflation, whereas the reverse holds only partially. This property of our data set supports the view that the time series we have included are relevant for modelling inflation. As expected, a relationship exists between money and credit to the private sector. Interestingly, global money Granger-causes global commodity developments. More straightforwardly, GDP Granger-causes credit and public debt and house prices Granger-cause GDP and credit, most likely via collateral and wealth effects. House prices seem to be primarily linked to interest rates and, in part, to developments in public debt. This initial inspection of the dataset this suggests reasonable relationships among the variables. It points to the use of a system of equations to investigate further the interrelations across the global variables and to better gauge their impact on inflation.

\section{METHODOLOGY AND EMPIRICAL ANALYSIS}

Inspection of the time series as in Section 3 points to the existence of several relationships among our variables. A vector autoregressive (VAR) model is the proper econometric methodology to account for such interactions and to explore propagation channels. All variables are endogenous in a VAR system of equations. Consequently, this methodology helps to track potential feedback effects and interrelationships.

\subsection{Empirical framework and practical approach}

As a starting point we consider a traditional reduced-form VAR model formulated as a polynomial in the lag operator $L$ :

$$
\Pi(L) X_{t}=\gamma_{0}+\varepsilon_{t}
$$

$t=1, \ldots, T, \varepsilon_{t} \sim \mathrm{N}(0, \Omega)$

where $X_{t}$ is the vector of endogenous variables, $\Pi(\cdot)$ is a matrix polynomial in the lag operator such that $\Pi(L)=I+\sum_{i=1}^{p} B_{i} L^{i}$ with $p$ lags, $\gamma_{0}$ is the vector of unrestricted constants and $\varepsilon_{t}$ is 
a normally distributed zero mean and $\Omega$ variance error term. Autocorrelations in the residuals is excluded. However, $\Omega$ is not a diagonal matrix and covariance across the variables is allowed. More formally, $E\left(\varepsilon_{t} \varepsilon_{s}^{\prime}\right)=\omega$ for each $t=s$ and $E\left(\varepsilon_{t} \varepsilon_{s}^{\prime}\right)=0$ for each $\mathrm{t} \neq \mathrm{s}$.

To proceed in the analysis we need to design a concrete approach to estimate the full model based on eight variables. The variables are taken in log-changes and a constant is added to the model. The full vector of endogenous variables is:

$$
X_{t}=\left[\Delta Y_{t}, \Delta D_{t}, \Delta C P I_{t}, \Delta R P P_{t}, \Delta M_{t}, \Delta C R P_{t}, \Delta C O M_{t}, I N T_{t}\right]
$$

Specifically the model includes real output $\left(\Delta Y_{t}\right)$, public debt growth $\left(\Delta D_{t}\right)$, consumer price inflation $\left(\triangle C P I_{t}\right)$, house price dynamics $\left(\triangle R P P_{t}\right)$, money growth $\left(\triangle M_{t}\right)$, private credit growth $\left(\triangle C R P_{t}\right)$, commodity inflation $\left(\triangle C O M_{t}\right)$ and the short-term interest rate $\left(I N T_{t}\right)$.

In practice, without the inclusion of some restrictions the parameters in the VAR are not identified and consequently some shocks to the system cannot be interpreted in a structural fashion. To a large extent, the set of variables included in $X_{t}$ is similar to those employed by Sousa and Zaghini (2007) and Belke et al. (2010a, b). We refer to these studies to define our identification scheme. For details on the structural VAR (SVAR) representation, see Annex C.

The SVAR can be employed to conduct several simulation exercises. Among them, we consider a structural impulse response function (IRFs) exercise and a forecast error variance decomposition exercise. Since the ordering of variables in our recursive identification structure is likely to influence the results, we conduct a sensitivity analysis in Section 4.3 to assess the potential influence of any specific ordering and check the robustness of the results.

Our base case ordering of the system in the SVAR follows from the view that monetary variables react faster to innovations stemming from the real and nominal economy than vice versa (Favero, 2011). Real activity, $Y$, is ordered first, as in Rueffer and Stracca (2006) and Sousa and Zaghini (2007). Since government spending has been ordered among the first variables in studies focused on fiscal issues (e.g., Blanchard and Perrotti, 2002), we also follow this approach.

Consumer price reactions to shocks are not assumed to be contemporaneous, since the prices of goods and services tend to be "sticky". Such price stickiness is typically attributed to frictions in labour and goods markets. By contrast, auction-based commodity markets are able to respond rapidly to overall macroeconomic conditions (Barsky and Kilian, 2002), and more generally to new information (Frankel, 1986). Moreover, they are characterised by fewer frictions in the price-adjustment process because market participants have more balanced information than the consumer goods and services counterparts (Browne and Cronin, 2007). Consequently commodity prices are assumed to respond contemporaneously to almost the entire set of innovations.

House prices are ordered similarly to Belke et al. (2010b) on the assumption that residential housing markets have a rather inelastic supply in the short-run. This can be related to several overlapping factors such as: the scarcity of land; restrictions on land utilisation; ${ }^{6}$ and transaction costs. Real factors (such as higher household incomes) are thus unlikely to have an immediate impact on house prices.

Drawing on the extensive money demand literature ${ }^{7}$ (summarised by Fischer and Pill (2010)), global money ${ }^{8}$ is modelled as in Sousa and Zaghini (2007). The equation represents a stylised money demand function with money expected to respond (negatively) to hikes in financing costs, and to other forces due to transaction, portfolio allocation motives and opportunity costs

\footnotetext{
e.g. new construction requires several steps of approval and regulation defines the number of days to obtain building permits; additionally also to renew buildings/spaces authorities approval is usually necessary.

For a review on the theoretical analysis on the demand for money see McCallum and Goodfriend (1988).

Sousa and Zaghini (2007) refer to global liquidity and we refer to global money. Both aggregates refer to a global variable made up of country specific definitions of broad money. The difference stems in the representativeness of the global variable. Sousa and Zaghini (2007) employ G5 economies whereas this paper employs a much broader set of countries - see Section 3.
} 
(Ericsson, 1998). To recall, consensus had grown around the idea of a stable ${ }^{9}$ long-run money demand (Poole, 1988; Lucas, 1988). Looking at short-term developments, one of the primary concerns was the potentially short-run instability of the demand function for money (e.g. Alvarez and Lippi, 2011). Indeed, short-run demand has been detected to be unstable in several studies (inter alia, Goldfeld and Sichel, 1990). Little is known about how short-term shifts in money demand, or changes in the quantity of money demanded, affect the relationship between money and other macro aggregate variables and thereby how they can possibly impact on monetary policy transmission. Hence, it is worth to look at demand shocks to improve our understanding of the effects - if any - of temporary money shifts on real and nominal variables.

As described in Section 3.2, the money variable has been constructed using the broadest available monetary aggregate for every single country in each period. Our model includes the quarterly changes of the variables and the short run variations in the broad money aggregate can be interpreted as demand driven components - i.e., exogenous increases in liquidity preference. Global credit is modelled as a function of global money, income, real assets and financing costs. Specifically, increases in wealth, as captured by house price developments, are expected to exert a positive impact on private credit via balance sheet effects. Short-term interest rates are ordered as in Belke et al. (2010b) assuming that respond immediately to the overall set of available information.

Last but not least, an outcome of the aggregation procedure (outlined in Section 3.1) relates to the inherent treatment of the country specific idiosyncratic components. The existing literature on the potential "aggregation bias", implicit in using aggregated series - i.e. world data in our study, considers two main fundamental approaches. Gorman (1953) and Theil (1954) studied in a static framework the problem of aggregation in econometrics analysing the aggregation error resulting from aggregating equations based on microdata equations. Lippi and Forni (1990) propose a more general representation that emphasizes the dynamics as a possible source of aggregation bias. The latter approach is based on unobserved components while the former representation is based on observable series. By contrast, Grunfeld and Griliches (1960) show that the aggregation error can actually become an aggregation gain under certain assumptions.

Being aware of these aggregation issues and the underlying literature, we do not intend to investigate the aggregation bias at its roots. We follow Belke et al. (2010) in our analysis and, consequently, we focus on the common co-movement of the aggregate. The basic intuition is that an idiosyncratic component is, loosely speaking, something that disappears with aggregation. Factor models reflect this idea. To this end, we draw from that literature and we apply the underlying assumptions of standard factor models to our constructed series. Then, the set of aggregated variables is driven by a common component, if idiosyncratic components are mutually orthogonal, because the variance of an aggregated idiosyncratic component tends to zero as the number of cross sections tends to infinite. This permits the emergence of the common component as primary driver. Under this assumption the shocks in our model are taken as common global shocks - see literature review in Section 2 - and consequently responses to the shocks are interpreted as reactions to common global innovations applied to the system.

\subsection{Empirical results}

Other than the short-term interest rate, all variables enter our model as log first differences.

The first step of our analysis is to investigate the unit root properties of the series listed in Section 3 over the full sample period. We use an extended set of statistics to test the order of integration of the level and first difference of each variable, namely: Dickey-Fuller (DF), Augmented Dickey-Fuller (ADF), Elliot, Rothenberg and Stock (ERS) and Ng-Perron (NP). The

\footnotetext{
9 Among others, Ball (2001), Brand and Cassola (2004) and Holtemöller (2004) have identified stable long-run demand functions. Recently, and including data after 2001, Dreger and Wolters (2010) were able to identify a stable long-run money demand relationship for the euro area.
} 
number of lags for the DF and the ADF tests are selected using the Akaike Information Criterion (AIC), while we use the Bartlett spectral estimation method to choose the truncation point for the Newey-West adjustment required for calculating the ERS statistic and the Schwarz info criterion for the lag length selection in the NP statistic.

The test results in Table 3 show that most first differences of the series are integrated of order zero and most levels are integrated of order one at $95 \%$ confidence level.

Table 3

Unit root tests

\section{First Differences}

\begin{tabular}{|c|c|c|c|c|c|c|c|}
\hline & \multirow{2}{*}{ DF } & \multirow{2}{*}{ ADF } & \multirow{2}{*}{ ERS } & \multicolumn{4}{|c|}{$\mathbf{N P}$} \\
\hline & & & & $M Z a$ & $M Z t$ & $M S B$ & $M P T$ \\
\hline $\boldsymbol{Y}$ & -3.852 & -3.074 & 0.306 & -18.794 & -3.065 & 0.163 & 1.304 \\
\hline$M$ & -8.242 & -3.434 & 0.073 & -347.071 & -13.172 & 0.038 & 0.072 \\
\hline CPI & -1.260 & -2.744 & 0.067 & -159.762 & -8.938 & 0.056 & 0.153 \\
\hline$R P P$ & -2.000 & -3.091 & 0.047 & -541.537 & -16.455 & 0.030 & 0.045 \\
\hline$C R P$ & -3.534 & -4.212 & 0.268 & -348.996 & -13.210 & 0.038 & 0.261 \\
\hline COM & -10.733 & -5.383 & 0.161 & -160.774 & -8.961 & 0.056 & 0.160 \\
\hline$D$ & -3.674 & -4.049 & 0.108 & -299.660 & -12.230 & 0.041 & 0.094 \\
\hline \multicolumn{8}{|c|}{ Levels } \\
\hline & \multirow{2}{*}{ DF } & \multirow{2}{*}{ ADF } & \multirow{2}{*}{ ERS } & \multicolumn{4}{|c|}{$\mathbf{N P}$} \\
\hline & & & & $M Z a$ & $M Z t$ & $M S B$ & $M P T$ \\
\hline $\boldsymbol{Y}$ & 0.498 & 2.203 & 17182.390 & 1.564 & 11.305 & 7.226 & 3703.880 \\
\hline$M$ & 0.403 & 1.472 & 0.100 & 1.543 & 10.126 & 6.563 & 3043.308 \\
\hline$C P I$ & -0.419 & -2.032 & 949.728 & 1.169 & 4.804 & 4.108 & 1108.860 \\
\hline$R P P$ & 1.042 & 1.824 & 2737.473 & 1.034 & 2.992 & 2.893 & 537.640 \\
\hline$C R P$ & 1.126 & 2.554 & 14.946 & -99.888 & -7.036 & 0.070 & 1.031 \\
\hline$C O M$ & 0.833 & -0.659 & 1.116 & 1.579 & 3.136 & 1.986 & 287.100 \\
\hline$D$ & 0.859 & 0.458 & 54.051 & 2.199 & 2.667 & 1.213 & 124.163 \\
\hline$I N T$ & -0.444 & -0.562 & 0.029 & -1023.470 & -22.614 & 0.022 & 0.029 \\
\hline
\end{tabular}

Note: Bold numbers refer to at least $10 \%$ level

Test critical values:

Augmented Dickey-Fuller test statistic (ADF)

Dickey-Fuller test statistic (DF)

Elliott-Rothenberg-Stock test statistic (ERS) - Newey-West bandwidth using Bartlett Kernel

Ng-Perron test statistics (NP) - Newey-West bandwidth using Bartlett Kernel

$\begin{array}{lrrr} & 1 \% \text { level } & 5 \% \text { level } & 10 \% \text { level } \\ & -3.463 & -2.876 & -2.574 \\ & -2.577 & -1.942 & -1.616 \\ & 1.916 & 3.176 & 4.340 \\ \text { MZa } & -13.800 & -8.100 & -5.700 \\ \text { MZt } & -2.580 & -1.980 & -1.620 \\ \text { MSB } & 0.174 & 0.233 & 0.275 \\ \text { MPT } & 1.780 & 3.170 & 4.450\end{array}$

Source: Authors' calculations. 
The only exceptions are the CPI and INT series. For CPI, some evidence suggests integration of order (1) for the first differenced variable at $90 \%$ confidence level and for INT integration of order (1) is partially detected in the level variable. Specifically, the null hypothesis of a unit root is not rejected for both variables by the DF statistics and by the ADF statistics for the interest rate variable. The hypothesis, however, is rejected by the non-parametric PP and NP tests. In general, the ADF test has very low power against I(0) alternatives that are close to being I(1). That is, unit root tests cannot distinguish highly persistent stationary processes from nonstationary processes very well. The tests proposed by Elliot et al. (1996) and Ng and Perron (1995; 2001) should be able to have more power against very persistent alternatives. Given these arguments and evidence, we proceed on the basis that the first difference of CPI and the level of INT are integrated of order zero as well as the first difference of the other series.

Concerning the properties of the VAR employed for the empirical examination, the usual selection criteria to detect the number of lags point to seven lags (see Table 4). More specifically, the lags are selected using the final prediction error and the Akaike information criterion. For completeness, a test on the autocorrelation of the residual is also proposed. It should be recalled that the testable assumption of no autocorrelation in the residuals has some important implications for the economic interpretation of the results and it is a relevant assumption for our model given the long time horizon perspective. As stressed in Hendry (1995) and Jusélius (2006), autocorrelated residuals would imply that agents do not use the information in the data as effectively as possible. A LM-test for autocorrelation in the residuals based on twelve lags suggests no autocorrelation (see Table 5). It implies that there are not omitted variables issues.

Table 4

Lag length criteria tests

VAR - eight variables - INT, Y, CPI, M, CRP, RPP, D, COMM

\begin{tabular}{ccccccc} 
Lags Number & LogL & LR & FPE & AIC & SC & HQ \\
\hline 0 & 4727.6992 & NA & $1.02 \mathrm{E}-31$ & -48.65669 & -48.52194 & -48.60213 \\
1 & 5773.8475 & 2097.814 & $4.09 \mathrm{E}-36$ & -58.78193 & $-57.56912^{*}$ & -58.15472 \\
2 & 5869.0310 & 168.052 & $3.15 \mathrm{E}-36$ & -59.66631 & -56.81254 & $-58.29083^{*}$ \\
3 & 5928.2911 & 110.5403 & $3.24 \mathrm{E}-36$ & -59.96183 & -55.68562 & -58.17577 \\
4 & 5991.0658 & 106.5639 & $3.35 \mathrm{E}-36$ & -60.37939 & -54.59493 & -57.69037 \\
5 & 6054.1388 & 102.3567 & $3.82 \mathrm{E}-36$ & -61.17976 & -53.50732 & -57.24121 \\
6 & 6109.0899 & 80.74722 & $3.78 \mathrm{E}-36$ & -62.72674 & -52.33598 & -56.79511 \\
7 & 6179.1926 & $106.1426^{*}$ & $2.97 \mathrm{e}-36^{*}$ & $-64.64517^{*}$ & -51.32083 & -56.26529 \\
8 & 6233.1036 & 69.3474 & $4.51 \mathrm{E}-36$ & -58.89798 & -50.13877 & -55.89167 \\
9 & 6278.1906 & 56.20919 & $6.04 \mathrm{E}-36$ & -58.703 & -48.86573 & -55.35113 \\
10 & 6336.0588 & 64.7556 & $7.28 \mathrm{E}-36$ & -58.63978 & -47.72446 & -54.71961 \\
\hline \hline
\end{tabular}

Note: ${ }^{*}$ indicates lag order selected by the criterion

LR: sequential modified LR test statistic (each test at 5\% level)

FPE: Final prediction error

AIC: Akaike information criterion

SC: Schwarz information criterion

HQ: Hannan-Quinn information criterion

Source: Authors' calculations. 
Table 5

LM test for autocorrelation in the residuals

\begin{tabular}{ccc}
\hline \hline \multicolumn{2}{c}{ VAR - variables - Y, CPI, M, INT, CRP, RPP, D, COMM } \\
Number of Lags $-\mathbf{h}$ & LM-Statistics & Prob \\
\hline 1 & 66.30781 & 0.3973 \\
2 & 52.02793 & 0.8583 \\
3 & 61.22315 & 0.5753 \\
4 & 71.60657 & 0.2402 \\
5 & 50.41512 & 0.8921 \\
6 & 92.56915 & 0.1131 \\
7 & 54.56865 & 0.7935 \\
8 & 76.51414 & 0.1358 \\
9 & 76.69345 & 0.1328 \\
10 & 51.47616 & 0.8705 \\
11 & 58.68959 & 0.6641 \\
12 & 67.41265 & 0.3612 \\
\hline \hline
\end{tabular}

Note: Null Hypothesis: no serial correlation at lag order h.

Source: Authors' calculations.

We will use the model to conduct two exercises: (1) an IRF exercise to analyse the interlinked responses of the variables to one standard deviation innovations; and (2) a variance decomposition.

We recognise that an effective identification of all shocks in such a large system (as designed in Section 4.1) can be difficult. Further work on the sensitivity of the results is needed to determine the exact form of the identifying restrictions. We are interested in uncovering the relationships among the variables and are careful to interpret all the orthogonalised shocks as structural. For sure, there is a risk in so doing. Yet the exercises are worthwhile in that: (i) the restrictions of our model are similar to other previous studies (see Section 4.1), so there is a basis for comparison in the literature; and (ii) responses to some (most) shocks reflect our ex-ante expectations (and results from previous studies), offering support to our economic interpretation.

An initial check of the overall impulse responses gives reasonable results and conforms to both expectations and other studies. Charts 2 to 6 show a collection of impulse responses to a one standard deviation innovation derived from the fully-fledged model over a twenty period window. All shocks are calibrated to be one standard deviation of the log-change of the respective series.

Overall, these results provide a good qualitative benchmark and reveal economically meaningful relationships among the variables employed. In line with previous literature (see Section 2), consumer prices react significantly - but only after a considerable lag - to global demand money shocks, whereas they respond almost immediately to commodity price shocks. This is evidence of commodity prices inflating consumer good prices via a cost-push mechanism. Additionally, the CPI response to a commodity shock is short-lived relative to its reaction to a global money shock. Commodity prices react immediately money and, after a couple of periods, to output. The latter relationship can be interpreted as a reaction of commodity prices to higher demand, which in the short-run push up commodity prices given inelastic supply. The relationship between commodity prices and global money suggests that commodity prices initially overshoot 
their new equilibrium values in response to a global money demand shock and possibly increase inflation via a global monetary expansion channel. Last but not least, the overall reaction to interest rates is in line with the literature, including the negative response of money to a positive shock in interest rates.

\section{Chart 2}

Impulse response function - Global demand money shock (response to one S.D. innovations and \pm 2 S.E. bands)
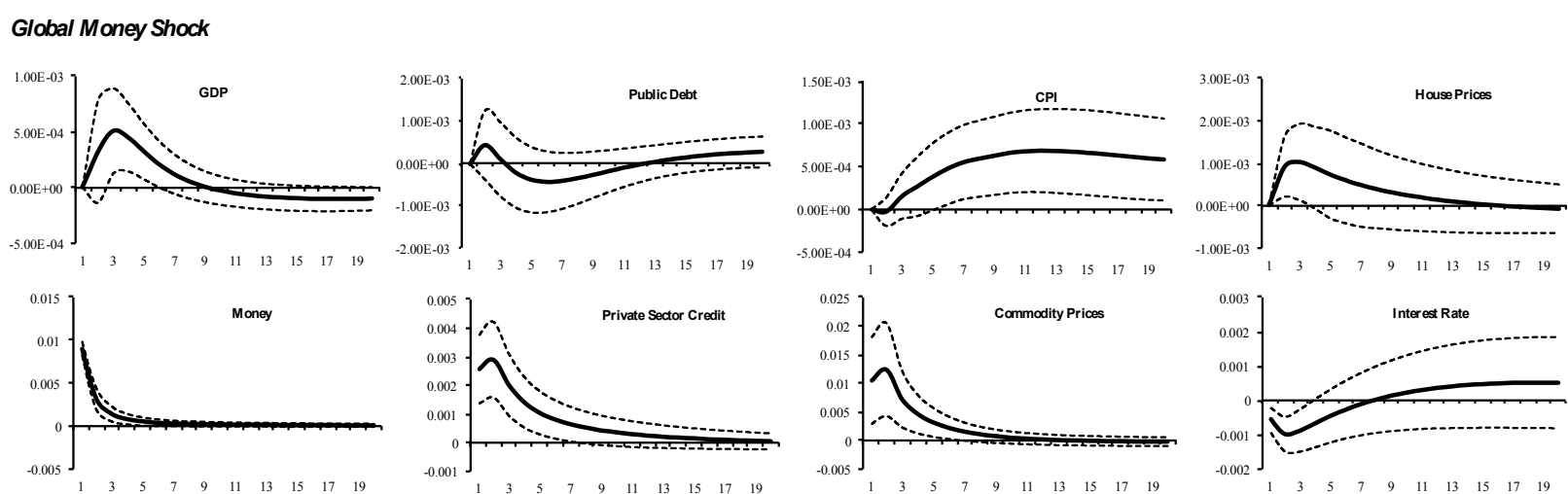

Note: the figures represent a deviation from the model based baseline. Confidence intervals display 2 standard deviations and are calculated via the studentized Hall bootstrap method. The shock is equal to 1 standard deviation of the variable.

Source: Authors' calculation.

Chart 2 reports the responses to a global demand money shock as defined in Sousa and Zaghini (2007). Interestingly, this shock interacts - within the confidence bands - with almost all the variables included in the system. The global money shock gives rise to a significant lagged response of inflation $(\triangle C P I)$. More specifically, inflation responds significantly (measured by the \pm 2 S.E. bands) after six periods (i.e. one year and a half). This evidence stresses the relevance of the relation between money growth and inflation whereas no response of inflation to private credit expansion is detected. This suggests looking at broad money instead of credit as a measure of global liquidity when we are interested in an assessment of potential inflation developments and risks.

Commodity prices $(\triangle C O M)$ respond positively and almost immediately to a global money shock. This finding helps to sustain further the idea that monetary aggregates may convey some useful information about the development in commodity prices. Browne and Cronin (2007) support this view. They used a cointegrating VAR estimated on US data and they found that commodity prices overshoot their new equilibrium value in response to a money shock and such a deviation has a significant explanatory power for consumer price inflation. This evidence becomes even more relevant for the understanding of the recent dynamics in commodity prices which can be explained as too much liquidity chasing too few assets (i.e. reflected in commodity prices) given the growing demand from emerging markets. The statistically significant effect of such a shock is short lived since it does not last for more than four periods.

Private credit $(\triangle C R P)$ responds positively to global money shocks. An expansion in the monetary aggregate growth leads to a temporary expansion in credit growth. This channel exemplifies the financial stability competences and relevance of larger financial and monetary players able to influence global money growth and to affect global developments in the system including credit.

House prices $(\triangle R P P)$ have a short lived and limited positive reaction to global demand shocks whereby a positive increase in money fuels a positive reaction in asset values also supported by a reduction of financing costs. In fact, interest rates (INT) are reported to decrease after a global money shock. Last but not least, the aggregate output $(\Delta Y)$ has a limited and short-lived 
positive reaction - suggesting that global money demand shocks have - even if channelled via the previously highlighted linkages - a somewhat limited and temporary, but positive, spillover effect on economic activity performance.

Chart 3

Impulse response function - Financing cost shock (response to one S.D. innovations and \pm 2 S.E. bands)
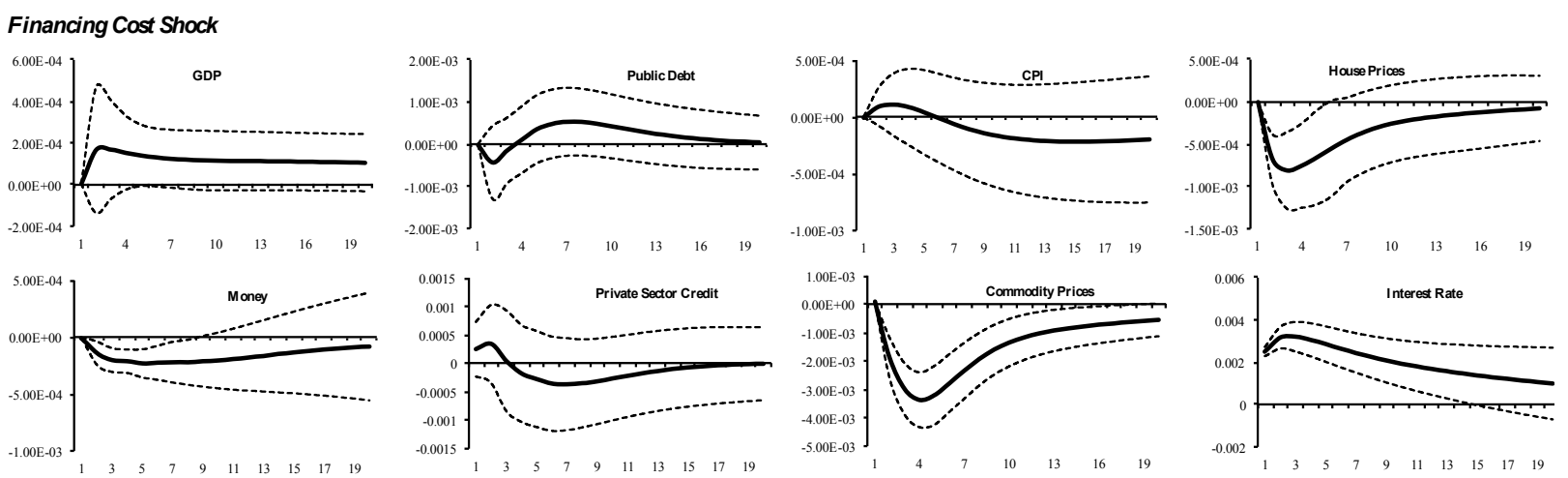

Note: the figures represent a deviat ased baseline. Confidence intervals display 2 standard deviations and are calculated via the studentized Hall bootstrap method. The shock is equal to 1 standard deviation of the variable.

Source: Authors' calculations.

Chart 3 reports the responses of the system to a financing cost shock. Global house prices $(\triangle R P P)$ respond negatively to positive interest rate innovations. We anticipate that this is basically the most sizeable response of house prices to any shock. However, it does not contradict the traditional findings in the boom and bust literature (e.g. Alessi and Detken, 2009) where house price corrections are correlated to credit dynamics and other variables. On the contrary, it supports the idea of employing a regional or country specific perspective ${ }^{10}$ to analyse house prices and housing market dynamics. Global house price developments seem to be primarily influenced by global developments in the cost of financing. This finding clears the way for another of inflation transmission channel moving from interest rates (financing costs) to inflation, via house price developments, which is discussed in more detail below.

Global money $(\Delta M)$ responds immediately and negatively to a financing cost shock as expected. However the response is short-lived. This confirms the relevance of an asset motive to hold money. Shocks in financing costs change temporarily the portfolio allocation across assets, including money holdings. This finding is similar to those available for single country models; however the response is not long-lasting.

Commodity prices $(\triangle C O M)$ respond negatively to a financing cost shock. There can be multiple channels at play. First, if financing costs move higher, then agents are less willing to hold inventories, other things being equal. Consequently, they will reduce inventories. This effectively lowers demand for commodities and therefore their prices. Second, a negative financing cost shock (increase in cost of financing) may make more convenient to liquidate commodities not extracted yet in order to earn interest on the proceeds from the sale - thus increase the likelihood of extracting known commodities buried in the ground.

10 Such a perspective can be applied to single countries and regions (e.g. US and the euro area) or to a set of countries pooling the country specific observations as it has been frequently done in the boom/bust literature. 


\section{Chart 4}

Impulse response function - Commodity cost shock (response to one S.D. innovations and \pm 2 S.E. bands)
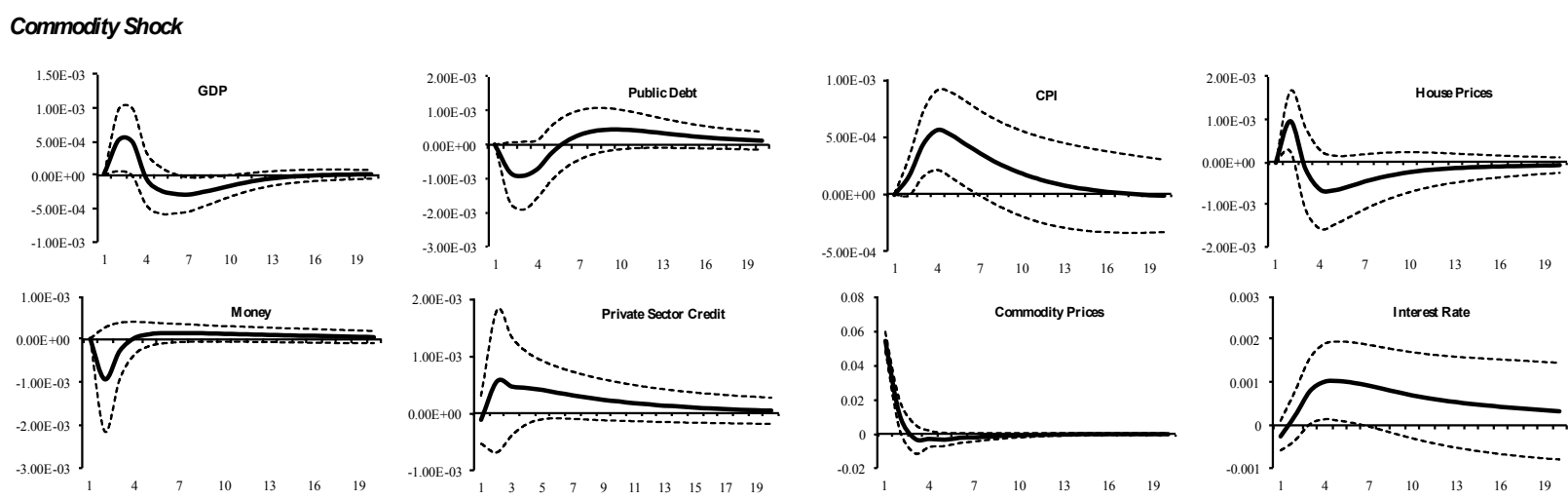

Note: the figures represent a deviation from the model based baseline. Confidence intervals display 2 standard deviations and are calculated via the studentized Hall bootstrap method. The shock is equal to 1 standard deviation of the variable.

Source: Authors' calculations.

Chart 4 reflects the responses to a global commodity shock. Inflation $(\triangle C P I)$ reacts almost without any lag to commodity shocks. This is due to the inclusion of consumer goods heavily exposed to commodity fluctuations in the basket of consumer price indexes. Similar evidence has been found in Sousa and Zaghini (2007). However, the impact is not long lasting. Our results confirm on the one hand a significant commodity price pass-through effect on inflation (see Ferrucci et al., 2010) when consumer prices tend to respond to shocks originated in the upstream level of the production chain (e.g. commodity prices) with shorter gestation lags than to money. On the other hand, commodity price inflation per se has not generally spawned strong secondround effects on inflation (see Cecchetti and Moessner, 2008). All in all this evidence confirms the relevance of commodity price hikes for short-term inflation developments, and not vice versa. Such a channel can also be seen as an indirect response of inflation to a global money shock which set in motion immediate responses in commodities and, consequently, in inflation. Financing costs (INT) respond positively (increasing), and only after two/three quarters, to a shock in commodities reflecting a possible global reaction of monetary players to global commodity price surges.

\section{Chart 5}

Impulse response function - Global house price shock (response to one S.D. innovations and \pm 2 S.E. bands)
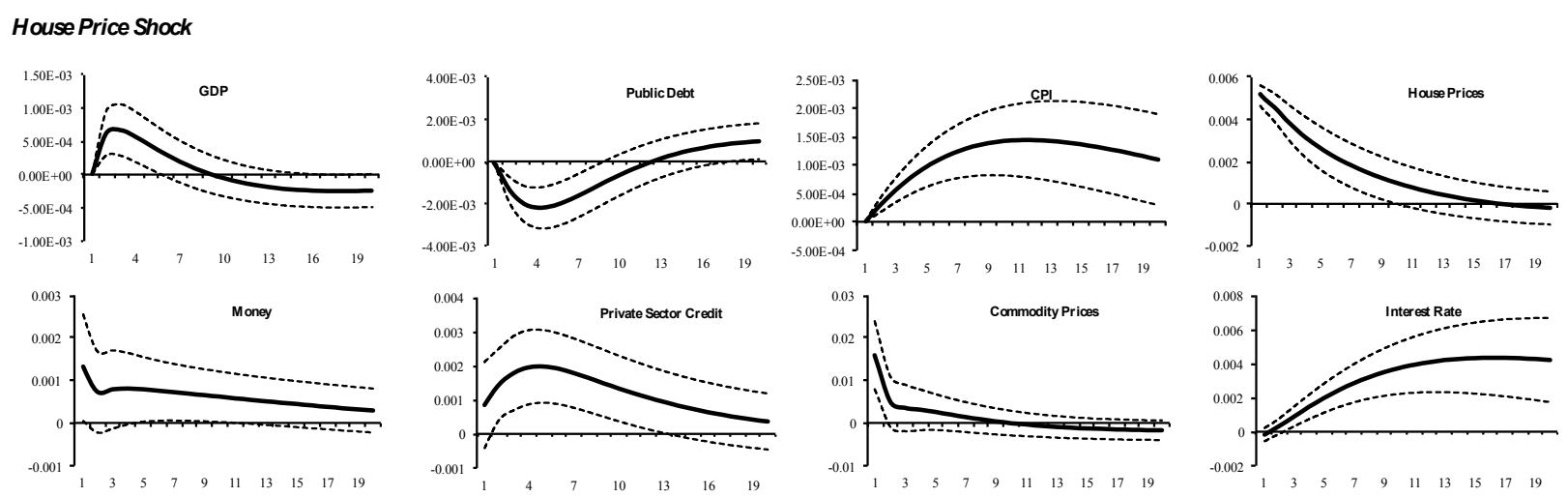

Note: the figures represent a deviation from the model based baseline. Confidence intervals display 2 standard deviations and are calculated via the studentized Hall bootstrap method. The shock is equal to 1 standard deviation of the variable.

Source: Authors' calculations.

Chart 5 shows the responses of the system to a global house price shock. Interestingly, inflation $(\triangle C P I)$ positively responds to a global house price shock with a short lag (see also Belke et al., 2010). Moreover, the reaction is long-lasting and persists for roughly 20 periods (i.e. five years). 
Such positive response confirms different transmission channels. It can be subject to a two-fold interpretation. First, increased house prices lead to an increase in households' net wealth. Higher net worth fosters consumption via a housing equity withdrawal channel (Aron et al., 2010), which allows transforming house price increases into actual transitory income and thereby higher consumption expenditure. Ultimately, this translates into stronger aggregate demand, which contributes to increased positive inflation dynamics. Second, the economic literature features a large number of in-depth studies concerning the relationship between asset returns and inflation (Fama and Schwert, 1977). Housing is an asset held by households. This interpretation, supported by our results, suggests that house price shocks have a positive impact on inflation since houses are a reserve value to hedge against inflation risk and, consequently, they generate a positive and statistically significant reaction in inflation dynamics (Kuan-Min et al., 2008).

Private credit growth $(\triangle C R P)$ responds significantly to house price innovations. Belke et al. (2010b) found a significant response of money to a house price shock and interpreted their finding as an effect of increased demand for credit because private credit was not included in their model. To the contrary our model includes also private credit. Therefore we can test this effect directly. First, we did not find a significant response of money to a positive house price shock. Our findings suggest however the existence of a collateral effect, which favours credit expansions and contractions. This evidence sustains the interpretation that house price decreases have substantially contributed to trigger (negative) credit dynamics, including the sharp decline over the recent crisis. This evidence concurs with Goodhart and Hofmann (2007) and Ferreira and Gyourko (2011). The latter study stressed that key players in the lending market responded to the market conditions and asset value dynamics. All in all, our model based evidence supports further attempts to study private credit developments as a function of the collateralised asset values.

Real GDP $(\Delta Y)$ growth is mildly responsive to house price innovations. This can be interpreted as a mild evidence of a positive wealth effect on aggregate consumption and ultimately total output. Financing costs (INT) are responsive to house price innovations. This could suggest that frictions in credit supply imply a rise in the price of credit with a booming demand for loans to finance an increasing demand for housing. Lastly, public debt $(\Delta D)$ responds negatively to positive house price shocks. This can be interpreted in the light of a portfolio reallocation, which highlights a substitution effect between public debt and house prices.

\section{Chart 6}

Impulse response function - Global public debt shock (response to one S.D. innovations and \pm 2 S.E. bands)
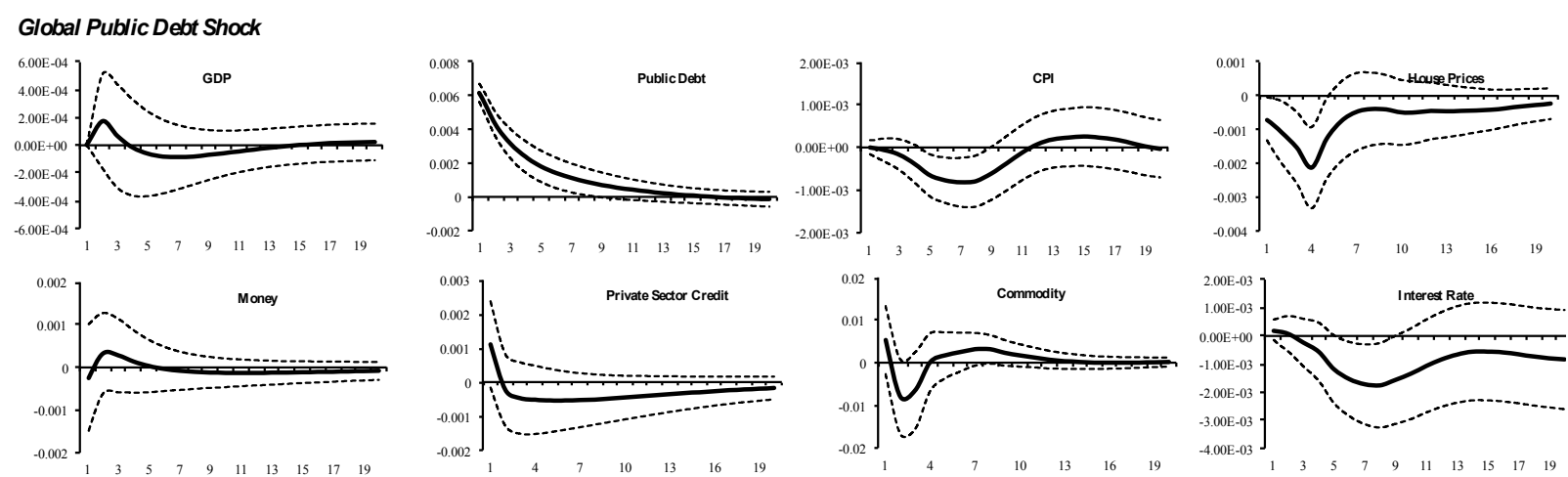

Note: the figures represent a deviation from the model based baseline. Confidence intervals display 2 standard deviations and are calculated via the studentized Hall bootstrap method. The shock is equal to 1 standard deviation of the variable.

Source: Authors' calculations.

The system shows also marginal and short-lived responses to a global public debt shock (see Chart 6). Inflation ( $\triangle C P I$ ) responds negatively to positive public debt shocks. Specifically, a positive public debt shock has a negative impact on inflation after four periods and the 
statistically significant response lasts for roughly five periods ahead (i.e. slightly more than one year). This suggests the existence of a mechanism working through demand and global money. In other words, an ex-post Ricardian effect is determined where an expansion in public expenditure (or a tax cut) determines a contraction in demand due to expected higher taxation. In turn this has a dampening effect on consumer prices. This result is in line with the empirical analysis conducted in Canzonieri et al. (2001) which supports the evidence of Ricardian regimes. In other words, so far and loosely speaking, fiscal dominance concerns did not drive a positive correlation between public debt and inflation. House prices $(\triangle R P P)$ respond negatively to positive public debt shocks. This can be interpreted in the light of a portfolio reallocation, which highlights a substitution effect between public debt and house prices.

All in all, inflation responds to most of the proposed shocks either almost immediately or with some lags. To further substantiate the findings on the transmission channels to global inflation, we analyse the results stemming from the forecast error variance decomposition. Chart 7 reports the forecast error variance decomposition of inflation based on the structural decomposition employed in the impulse response function exercise. Chart 7a shows the breakdown across all shocks whereas chart 7.b focuses only on those shocks described above and their relative contributions. Prima facie most of the results obtained from the IRFs exercise are confirmed.

\section{Chart 7}

Forecast error variance decomposition of inflation

\section{a. Forecast error variance decomposition of inflation}

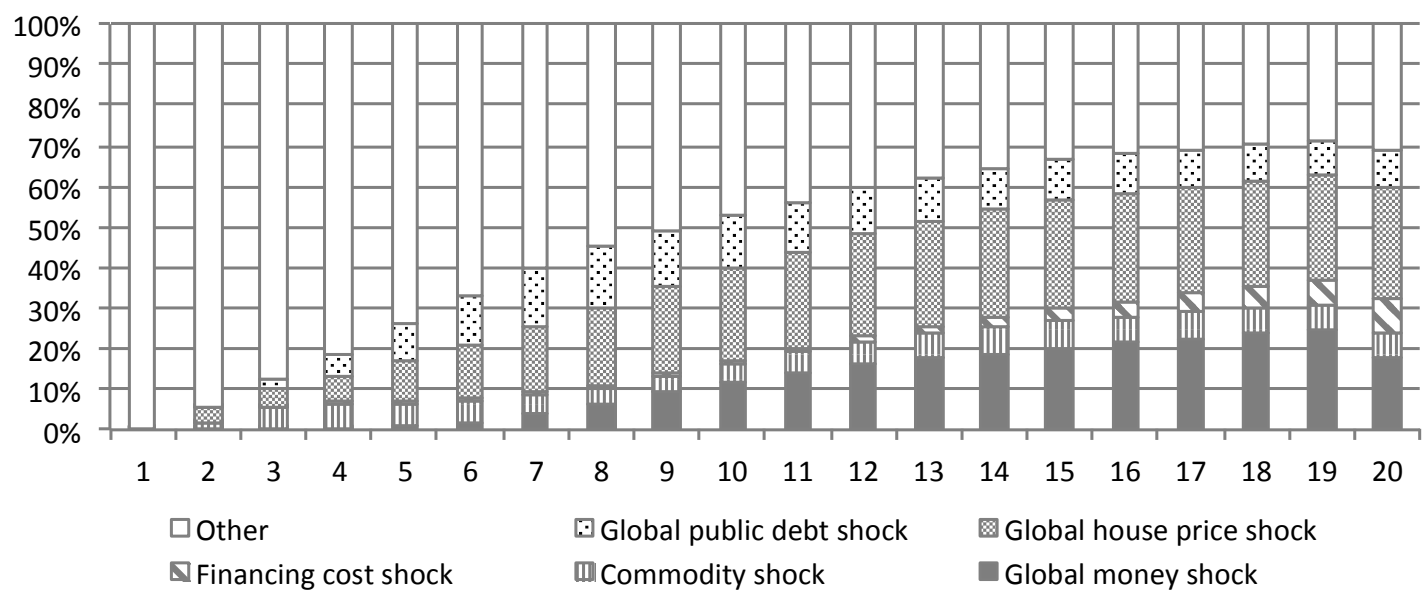

b. Variance decomposition - distribution across all shocks except "Other"

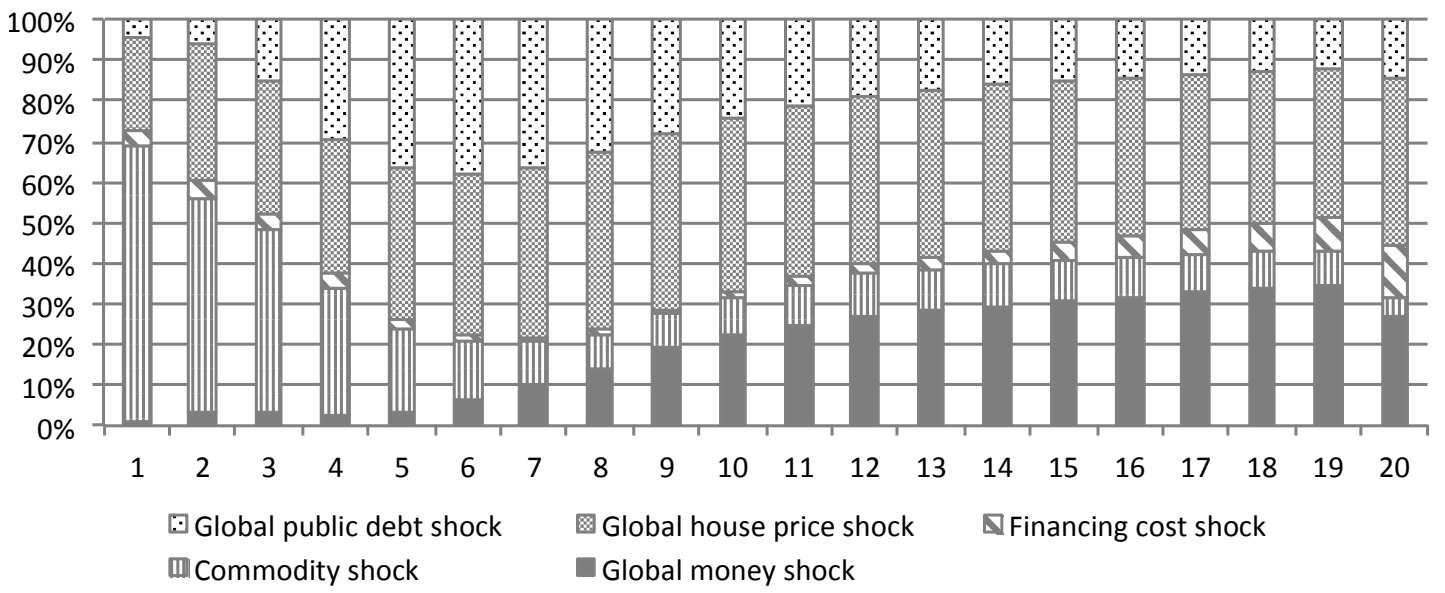

Note: the structural decomposition employed is the same of the IRFs exercise.

Source: Authors' calculations. 
An assessment of the variance decomposition suggests that commodity shocks do not contribute significantly to the forecast error variance of inflation in the medium term. After contributing to the variance of inflation by roughly 10 per cent in a one-year window, the commodity shock contribution steadily decreases over time. The house price shock contribution to the overall variance kicks in after some periods and it steadily increases over time to contribute almost thirty per cent after twenty periods. The money shock explains significantly more than 10 per cent of the inflation variance after ten periods and its contribution increases further above 20 per cent after eighteen periods. Interestingly, the public debt component explains roughly an average 10 per cent of the variance decomposition all over a twenty periods window. Financing cost shocks also contribute in the medium term with roughly 10 per cent.

\subsection{Robustness checks}

We have conducted several experiments to check the robustness of our model.

First we have conducted a robustness analysis "at the surface" of the model changing the lag length and the ordering to some of the variables. To assess the effect of the changes on the model we have conducted an impulse response exercise after the implementation of each change. Given the results in Section 4.2, we have ordered the house prices at first. As expected we do not detect any relevant difference. Additionally, we have swapped money and private credit. The results based on the impulse response exercise remain basically unchanged when compared to the results in Section 4.2. Last but not least, the commodity variable has been ordered at first on the basis of no contemporaneous correlation with the other innovations in the system. Again, no significant change is detected. Moreover, the model has been estimated using a lag length of two, as selected by the Hannan-Quinn information criterion (see Table 4). The results are fully confirmed, albeit with a slightly muted persistence in the responses for some variables.

\section{Chart 8}

Impulse response function model estimated over a restricted sample (1960-2000) - responses of CPI (response to one S.D. innovations and \pm 2 S.E. bands)

\section{Response of CPI}
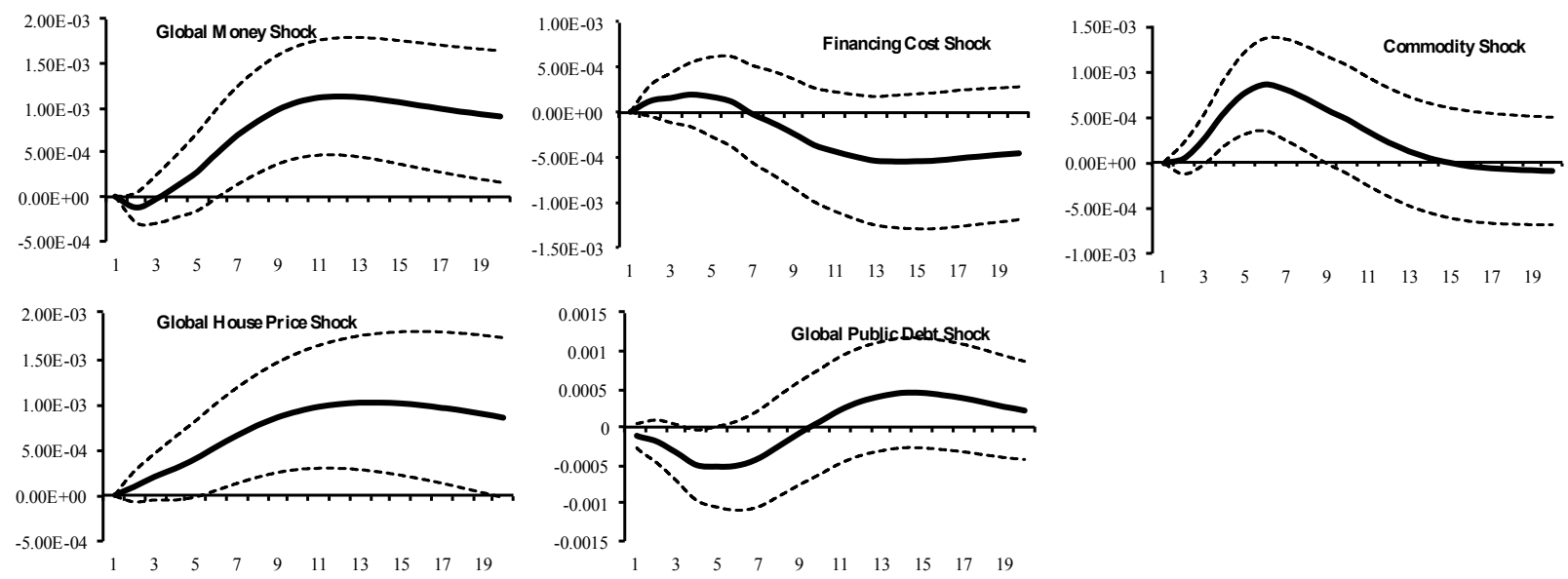

Note: the figures represent a deviation from the model based baseline. Confidence intervals display 2 standard deviations and are calculated via the studentized Hall bootstrap method. The shock is equal to 1 standard deviation of the variable.

Source: Authors' calculations.

Second, the estimation period has been reduced and restricted between 1960 and 2000. By doing so, we have excluded the last ten years of our sample which have been characterised by several notable economic events, namely: the last pronounced cycle in house prices, the latest credit expansion and the related financial innovation process, the strong and increased volatility 
in commodity prices culminating in the 2008 spike and, last but not least, the 2007-2010 global recession/financial crisis. An impulse response does not provide significantly different results from those described in Section 4.2.2. However, some differences are detected. These are documented in Chart 8 as concerns the response of CPI to the innovations in the system. ${ }^{11}$ Overall, the main difference lies in a muted response to global house prices innovations. Inflation seems to respond marginally less to house price shocks. Additionally, global money becomes the first factor explaining CPI forecast error variance after twenty periods. This stresses the relevant impact of the last housing cycle. However the overall results of our model estimated over the full period are confirmed.

Third, we have estimated our model based on a different construction of the variables. We have constructed aggregated variables using the countries available from $1965,{ }^{12}$ which basically represent the G7 economies. By doing so, we have excluded a large amount of countries which have impacted on the global developments only over the last two decades. For example, the representativeness of the new aggregate, measured in GDP-PPP terms, shrinks significantly from 1990 onward. Chart 9 reports the response of the CPI to all innovations ${ }^{13}$ considered in Section 4.2. These results broadly confirm and support the evidence provided in Section 4.2 - i.e. a marginally lower response of inflation to money growth is detected. This suggests that inflation developments for the G7 economies are certainly influenced by money growth in these economies. Furthermore, it hints that money growth in economies other than those included in the series (e.g. Asian emerging markets) have also contributed to the common component of inflation in advanced economies and elsewhere. The only detected difference concerns inflation responses to financing cost shocks. An increase in financing costs determines a limited and short-lived increase in inflation. This can be assimilated to the well-known and documented "price puzzle" (see Bernanke and Blinder, 1992; Christiano et al., 1994). ${ }^{14}$

\section{Chart 9}

Impulse response function model based on the variables constructed as described in section 4.3 - responses of CPI (response to one S.D. innovations and \pm 2 S.E. bands)

\section{Response of CPI}
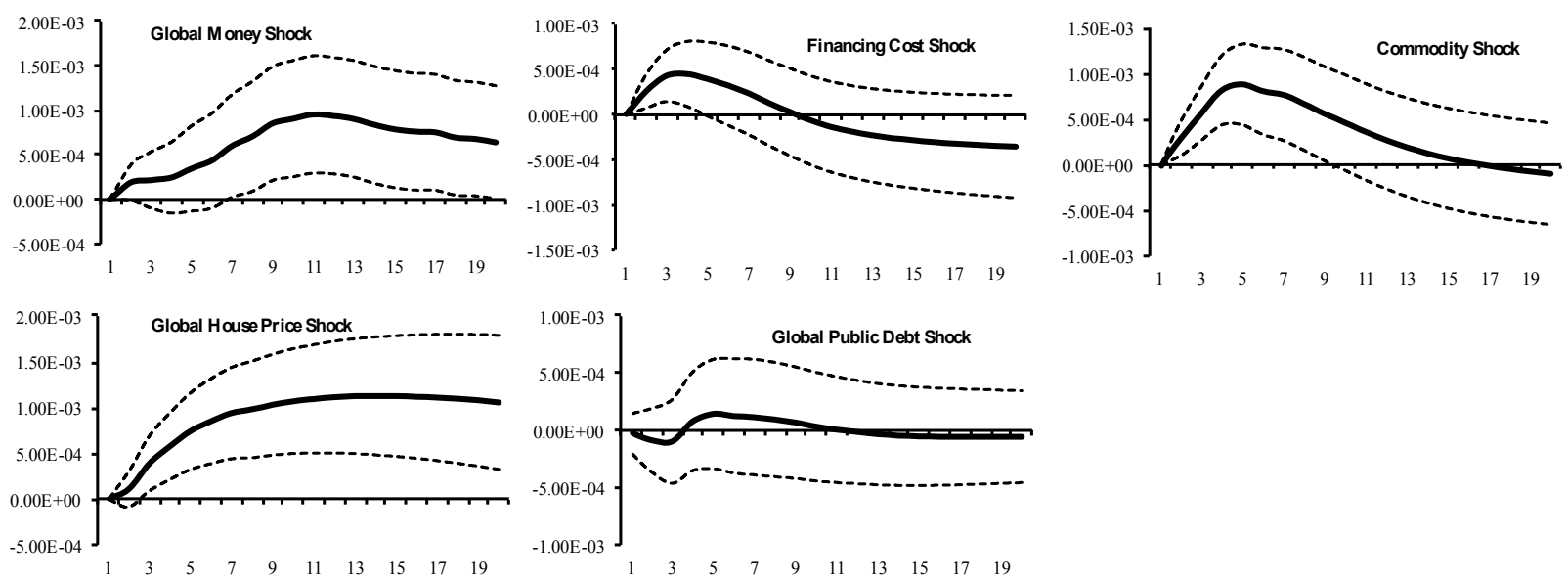

Note: the figures represent a deviation from the model based baseline. Confidence intervals display 2 standard deviations and are calculated via the studentized Hall bootstrap method. The shock is equal to 1 standard deviation of the variable.

Source: Authors' calculations.

The full set of IRFs can be provided upon request.

12 viz., Australia, Canada, France, Germany, Italy, Japan, the Netherlands, the United Kingdom and the United States of America.

13 Detailed and additional results for these robustness checks are available from the authors upon request.

14 One explanation of the "price puzzle" is that central banks respond to expectations of future inflation by raising rates. However the raise may not be enough to prevent a surge in inflation. As a result interest rates hikes are followed by a positive response of inflation. An alternative explanation relates to central banks reactions to supply shocks by raising rates. Rates can be raised not enough to extinguish the inflationary consequences of the supply shock. 


\section{CONCLUDING REMARKS}

In this study, we examine from a global perspective and for the 1960-2013 period, the relationship between money, asset prices (real estate), commodity prices, public debt, private credit, GDP and inflation. Our results can be summarised as follows.

First, global money demand shocks affect inflation and also global commodity prices. Global commodity price shocks in turn affect inflation. These findings highlight an additional global transmission mechanism to inflation, which individual countries cannot control, via commodity prices.

Second, asset/property price dynamics appear to be driven primarily by financing cost shocks at the global level (rather than being driven by shocks to global money). Moreover, an increase in house prices exerts a positive influence on inflation at the global level suggesting that an interest rate channel may work via asset values.

From a policy perspective, two conclusions emerge. First, large monetary and financial players should recognise the implications of their policy and strategic decisions on global inflation dynamics directly via money growth and indirectly through the effect on commodity prices. Second, house prices seem to be influenced by financing cost shocks and lead inflation developments. In addition to financial stability considerations, this is another reason why global real estate price evolutions should be monitored closely.

\section{References}

Agnello, L. and L. Schuknecht (2009). Booms and busts in housing markets: Determinants and implications, ECB working paper no. 1071.

Alessi, L. and C. Detken (2011). Quasi real time early warning indicators for costly asset price boom/bust cycles: A role for global liquidity, European Journal of Political Economy 12(2), pp. 234-256.

Alvarez, F.E. and F. Lippi (2011). Persistent liquidity effects and long-run money demand, NBER working paper no. 17566.

Aron, J., J.V. Duca, J. Muellbauer, K. Murata and A. Murphy (2010). Credit, housing collateral and consumption: Evidence from the UK, Japan and the US, CEPR discussion paper no. 7876.

Ball, L. (2001). Another look at the long-run money demand, Journal of Monetary Economics 47(1), pp. 31-44.

Barsky, R.B. and L. Kilian (2002). Do we really know that oil caused the Great Stagflation? A monetary alternative, in B. Bernanke and K. Rogoff (eds.), NBER Macroeconomics Annual, MIT Press, pp. 137-183.

Belke, A., I. Bordon and T. Hendricks (2010a). Global liquidity and commodity prices: A cointegrated VAR approach for OECD countries, Applied Financial Economics 20(3), pp. 227-242.

Belke, A., W. Orth and R. Setzer (2010b). Liquidity and the dynamic pattern of asset price adjustment: A global view, Journal of Banking and Finance 34(8), pp. 1933-1945.

Benati, L. (2009). Long-run evidence on money growth and inflation, ECB working paper no. 1027.

Bernanke, B.S. and A.S. Blinder (1992). The Federal Funds rate and the channels of monetary transmission, American Economic Review 82(4), pp. 901-21.

Beyer A., J.A. Doornik and D.F. Hendry (2001). Constructing historical euro-zone data, Economic Journal 111(2), pp. 102-121.

Blanchard O. and R. Perrotti (2002). An empirical characterisation of the dynamic effects of changes in government spending and taxes on output, Quarterly Journal of Economics 117(4), pp. 1329-1368.

Bournot S., F. Koechlin and P. Schreyer P. (2011). 2008 benchmark PPPs: Measurement and uses, OECD statistical brief no. 50-17.

Brand C. and N. Cassola (2004). A money demand system for euro area M3, Applied Economics 8(4), pp. 817-838. Browne F. and D. Cronin (2007). Commodity prices, money and inflation, ECB working paper no. 738.

Canzoneri, M.B., R.E. Cumby and B.T. Diba (2001). Is the price level determined by the needs of fiscal solvency? American Economic Review 91(5), pp. 1221-1238.

Cecchetti, S.G. and R. Moessner (2008). Commodity prices and inflation dynamics, BIS Quarterly Review 08(4).

Ciccarelli, M. and B. Mojon (2010). Global inflation, Review of Economics and Statistics 92(3), pp. 524-535.

Cochrane, J.H. (2001). Long-term debt and optimal policy in the fiscal theory of the price level, Econometrica 69(1), pp. 69-116. 
Christiano, L.J., M. Eichenbaum and C. Evans (1994). The effects of monetary policy shocks: Evidence from the flow of funds, FRB Chicago working paper no. 94-2.

D’Agostino, A. and P. Surico (2009). Does global liquidity help to forecast US inflation? Journal of Money, Credit and Banking 2(41), pp. 479-489.

Elliot, G., T.J. Rothenberg and J.H. Stock (1996). Efficient tests for an autoregressive unit root, Econometrica 64(3), pp. $813-836$.

Dreger, C. and J. Wolters (2010). Investigating M3 money demand in the euro area, Journal of International Money and Finance 29(1), pp. 111-122.

Ericsson, N.R. (1998). Empirical modelling of money demand, Empirical Economics 23(2), pp. $295-315$.

Favero, C.A. (2001). Applied macroeconometrics, Oxford University Press.

Fama, E.F. and G.W. Schwert (1977). Asset returns and inflation, Journal of Financial Economics 5(2), pp. $115-146$.

Ferreira, F. and J. Gyourko (2011). Anatomy of the beginning of the housing boom: US neighbourhoods and metropolitan areas 1993-2009, NBER working paper no. 17374.

Ferrucci, G., R. Jiménez-Rodríguez and L. Onorante (2010). Food price pass-through in the euro area the role of asymmetries and non-linearities, ECB Working Paper no. 1168.

Fischer, B. and H. Pill (2010). Improving models of euro area money demand in L. Papademos and J. Stark (eds.) Enhancing monetary analysis, Frankfurt: European Central Bank, pp. 131-206.

Frankel, J.A. (1986). Expectations and Commodity Price Dynamics: The Overshooting Model, American Journal of Agricultural Economics 2(68), pp. 344-348.

Goldfeld, S.M. and D.E. Sichel (1990). The demand for money, in B. Friedman and F. Hahn (eds.) Handbook of Monetary Economics, Elsevier, pp. 300-356.

Goodhart, C.A.E. and B. Hofmann (2007). House prices and the macroeconomy: Implications for banking and price stability, Oxford University Press.

Gorman, W.M. (1953). Community preference fields, Econometrica 21(1), pp. 63-80.

Grunfeld, Y. and Z. Griliches (1960). Is aggregation necessarily bad? Review of Economics and Statistics 42(2), pp. 281-291.

Hendry, D.F. (1995). Dynamic econometrics, Oxford University Press.

Holtemöller, O. (2004). Aggregation of national data and stability of euro area money demand," in C. Dreger and G. Hansen (eds.) Advances in macroeconometric modelling (Papers and Proceedings of the 3rd IWH workshop in macroeconometrics), Baden-Baden: Nomos, pp. 181-203.

Heston, A., R. Summers and B. Aten (2011). Penn World Table Version 7.0, Center for International Comparisons of Production, Income and Prices at the University of Pennsylvania.

Juselius, K. (2006). The cointegrated VAR model: Methodology and applications, Oxford University Press.

Kuan-Min, W., L. Yuan-Ming and N.T.T. Binh (2008). Asymmetric inflation hedge of housing return: A non-linear vector error correction approach, International Real Estate Review 11(1), pp. 65-82.

Lucas, R.E. Jr. (1980). Two illustrations of the quantity theory of money, American Economic Review 70(3), pp. 1005-1014.

McCallum, B.T. and M.S. Goodfriend (1988). Theoretical analysis of the demand for money, FRB Richmond Economic Review 74(1), pp. 16-24.

McCandless, G.T. and W.E. Weber (2005). Some monetary facts, FRB Minneapolis Quarterly Review 19(3), pp. 2-11.

$\mathrm{Ng}, \mathrm{S}$. and P. Perron (1995). Unit root tests in ARMA models with data-dependent methods for the selection of the truncation lag, Journal of the American Statistical Association 90(2), pp. 268-281.

$\mathrm{Ng}, \mathrm{S}$. and P. Perron (2001). Lag length selection and the construction of unit root tests with good size and power, Econometrica 69(4), pp. 1519-1554.

Rueffer, R. and L. Stracca (2006). What is global excess liquidity, and does it matter? ECB working paper no. 696.

Shiller, R.J. (2009). Irrational exuberance, 2nd edition, Princeton University Press.

Sims, C.A. (1994). A simple model for study of the determination of the price level and the interaction of monetary and fiscal policy, Economic Theory 4(2), pp. 381-399.

Sousa, J.M. and A. Zaghini (2007). Global monetary policy shocks in the G5: A SVAR approach, Journal of International Financial Markets, Institutions and Money 17(5), pp. 403-419.

Stapledon, N.D. (2009). Housing and the global financial crisis: US versus Australia, Economic and Labour Relations Review 09(3), pp. 217-245.

Theil, H. (1954). Linear aggregation of economic relations, Amsterdam: North-Holland.

Woodford, M. (1995). Price-level determinacy without control of a monetary aggregate, Carnegie-Rochester Conference Series on Public Policy 43, pp. 1-46. 


\section{ANNEXES}

\section{A. Aggregation procedure and weights}

PPP-adjusted GDP levels measure the size of economies in volume terms and provide a more meaningful measure of the relative size of countries rather than simple exchange-rate based comparisons. ${ }^{1}$ For our purposes we are interested not only in a snapshot of relative volumes in a year, we aim at having the evolution of GDP volumes between countries and over time.

To do so we combine spatial and temporal observations using a sequence of current PPPs at an annual frequency. The use of this method based on time varying PPPs helps to take into account potential catching up processes and price convergence dynamics across countries and over time. In other words, a new set of price level and exchange rate data is taken up every period since prices and price structure is allowed to vary over time (Bournot et al., 2011). Comparisons over time need to incorporate and adjust for several effects such as relative price movements and relative volume changes. Such shifts can be negligible in a short-run perspective. Accordingly a constant PPPs approach can be appropriate to aggregate short time series. To the contrary, we are considering a fifty year horizon and ignoring the dynamic effects (e.g. relative price movements across countries) may generate a less precise representation of economic developments. This calls for the employment of a time varying-PPP approach. Last but not least, a time varying PPPs approach safeguards the sensitivity of the results from the choice of the base year.

In addition to the selection stage in the aggregation procedure, we follow a similar approach as in Belke et al. (2010) based on Beyer et al. (2001) to obtain aggregated global series. This aggregation procedure entails three steps. First, country weights are computed for each year. In detail, the weight of country $i$ for period $t$ is:

$$
w_{i, t}=\frac{G D P_{i, t}^{N o m} e_{i, t}^{p p p}}{\sum_{i=1}^{N_{t}} G D P_{i, t}^{N o m} e_{i, t}^{p p p}}
$$

where $G D P_{i, t}^{N o m}$ is the nominal GDP adjusted by the PPPs exchange rates $e_{i, t}^{p p p}$ given a set of countries $N$ in period $t$. The United States of America is the reference country for exchange rate and price level comparisons. Second, the quarter on quarter growth rate, $g_{i, t}^{j}$, in domestic currency is computed for each variable $j$ in each country $i$. The aggregate quarter on quarter growth rate is obtained combining country weights determined in eq. 1 with country specific growth rates:

$$
g_{t}^{j}=\sum_{t=1}^{N_{t}} g_{i, t}^{j} w_{i, t}
$$

The last step entails the construction of an index for each series $j$ and an initial value of 100 has been chosen.

$$
\text { Index }^{j}=100 * \prod_{t=1}^{T}\left(1+g_{t}^{j}\right)
$$

This procedure has been applied to all series but the commodity price index, which has been produced by the Economist, and it has country coverage comparable to our constructed series. The aggregation procedure has several advantages. On the one hand, it allows aggregating indexes such as the house price index and the consumer price index. On the other hand, it helps to

1 We have measured the hypothetical size of our country sample using exchange rate adjusted GDP only and compared it to the same measured based on GDP-PPPs adjusted. The former measure accounts for a larger share of world GDP than the latter. 
reduce the potential bias, which may originate in aggregating levels of variables with potentially different national definitions of money and private credit. Indeed, an aggregation of different definitions may sum up to a total, which does not reflect the effective proportions across countries. Additionally, the GDP-PPPs weights take also into account the size of the economies and their relative movement over time including also relative price adjustments and not only exchange rate movements. Last but not least, the constructed time series capture also the contribution of the emerging markets, which becomes clearly crucial over the last 20 years or so. Indeed, the representativeness of the index would have fallen well below the 68 per cent threshold without the inclusion of emerging markets.

\section{B. Data}

Data was collected from various international and national sources. The series employed covers a long period spanning from 1960 to 2010 or shorter depending on the country - for the starting date of the series in each country see Table 1 . Series for some variables and specific countries may entail more than one source. A combination of sources has been employed only when it has not been possible to find the required missing data from a common national and/ or international source. In order to guarantee a high degree of cross-country harmonisation, a common source principle has been applied as the preferred selection criteria. Moreover, when quarterly data was not available, a quadratic interpolation procedure was applied.

The following country abbreviations are used: AUS for Australia; AT for Austria; BE for Belgium; CAN for Canada; CHE for Switzerland; CHN for China; DNK for Denmark; ES for Spain; FI for Finland; FR for France; UK for United Kingdom; DE for Germany; GR for Greece; HKN for Hong Kong; IE for Ireland; IT for Italy; JPN for Japan; KOR for Korea; MYS for Malaysia; NL for the Netherlands; NOR for Norway; NZL for New Zealand; PT for Portugal; SGP for Singapore; SWE for Sweden; THA for Thailand; USA for United States of America; ZAW for South Africa.

The following abbreviations of sources are used: OECD: Organisation for Economic Co-operation and Development; ESA95: European System of National Accounts 95; ECB/ESCB: European Central Bank and European System of Central Banks (including individual National Central Bank); STAT: Eurostat and National Office of Statistics; BIS: Bank of International Settlements; IFS: International Financial Statistics - International Monetary Fund; GFD: Global Financial data; ECO: The Economist; HA: Haver Analytics; CEIC: CEIC Database

\section{Consumer price index (CPI)}

Consumer price indexes were collected from a single source.

Source: IFS.

\section{Money (M)}

Monetary variables were collected from different sources and refer to the broader monetary aggregate available for each country. M3 is employed when available; otherwise M2 or M1 aggregates have been used. It is worth nothing that the "liquidity spectrum" of such aggregate may vary across countries. A narrow definition of money, say M1, for country X can be a broad enough definition for country $\mathrm{Z}$.

Source: IFS, ECB/ESCB, GFD. 


\section{Gross Domestic Product (Y)}

Real GDP was collected from different sources.

Source: IFS, ECB/ESCB, GFD, HA, ESA95.

The weightings employed for the aggregation procedure in Section 3.1 are annual variables defined as GDP in purchasing power parity terms and obtained from the Penn World Table Version 7.0 - Alan Heston, Robert Summers and Bettina Aten, Penn World Table Version 7.0, Center for International Comparisons of Production, Income and Prices at the University of Pennsylvania, May 2011. http://pwt.econ.upenn.edu/php_site/ pwt_index.php

\section{Private credit $(C R P)$}

Private credit was primarily obtained from as the IMF's International Financial Statistics, lines $22 \mathrm{~d}$ and $42 \mathrm{~d}$, which measure claims on the private sector by commercial banks and other financial institutions. The harmonized BIS database and ECB database for EU countries has also been used. Source: IFS, ECB/ESCB, BIS.

\section{$\underline{\text { Public debt }}($ D)}

For a reference to the IMF database employed see S.M.A. Abbas, N. Belhocine, A.A. ElGanainy and M.A. Horton (2010), A Historical Public Debt Database, Working Paper No. 10/245

Source: IMF.

\section{House prices $(R P P)$}

Country: AUS; AT; BE; CAN; CHE; CHN; DNK; ES; FI; FR; UK; DE; GR; HKN; IE; IT; JPN; KOR; MYS; NL; NOR; NZL; PT; SGP; SWE; THA; USA; ZAW

Source: OECD, ECB/ESCB, STAT, HA, CEIC, BIS.

The series for FR, AUS and US were constructed employing additional sources not reported above. Moreover, FR was backdated with data from Conseil General de l'Environnement et du Developpement durable (CGEDD) - http://www.cgedd.developpement-durable.gouv.fr/home-pricesin-france-1200-2011-r137.html; US backdated with data from Robert J. Shiller, Irrational Exuberance, 2nd. Edition, Princeton University Press, 2009; AUS was backdated with Stapledon, N.D. (2009) "Housing and the Global Financial Crisis: US versus Australia" The Economic and Labour Relations Review; NL backdated with The Herengracht Index.

\section{Interest rates (INT)}

The preferred measure of short-term interest rates is defined as 3-months interest rates otherwise the shortest available maturity has been employed. Notably for AUS data has been backdated to before 1969 with the 3-year housing loan interest rates.

Source: IFS, HA, STAT.

\section{Commodity Prices (COM)}

The Economist Price Index has been calculated since 1851. Among others the index contains prices for foods and industrials. Moreover it is representative for prices of metals, non-metals, farm and non-farm products.

Source: ECO. 


\section{Methodology}

We consider a traditional reduced-form VAR model formulated as a polynomial in the lag operator L:

$$
\Pi(L) X_{t}=\gamma_{0}+\varepsilon_{t}
$$

$t=1, \ldots, T, \varepsilon_{t} \sim \mathrm{N}(0, \Omega)$

where $X_{t}$ is the vector of endogenous variables, $\Pi(\cdot)$ is a matrix polynomial in the lag operator such that $\Pi(L) X_{t}=\gamma_{0}+\varepsilon_{t}$ with $\mathrm{p}$ lags, $\gamma_{0}$ is the vector of unrestricted constants and $\varepsilon_{t}$ is a normally distributed zero mean and $\Omega$ variance error term. Autocorrelations in the residuals is excluded. However, $\Omega$ is not a diagonal matrix and covariance across the variables is allowed. More formally, $E\left(\varepsilon_{t} \varepsilon_{s}^{\prime}\right)=\omega$ for each $t=s$ and and $E\left(\varepsilon_{t} \varepsilon_{s}^{\prime}\right)=0$ for each $t \neq s$. It should be recalled that the testable assumption of no autocorrelation in the residuals has some important implications for the economic interpretation of the results and it is a relevant assumption for our model given the long time horizon perspective. As stressed in Hendry (1995) and Jusélius (2006), autocorrelated residuals would imply that agents do not use the information in the data as effectively as possible.

Without the inclusion of some restrictions the parameters in the VAR are not identified and consequently the shocks to the system cannot be interpreted in a structural fashion. To model the shocks we employ a decomposition similar to Sousa and Zaghini (2007) and for some variables to Belke et al. (2010b). Both papers are also employed as reference for the interpretation of some structural shocks. The reduced form VAR in equation 1.C can be written in a structural VAR (SVAR) representation:

$$
A(L) X_{t}=e_{t}
$$

where $A(L)=K+\sum_{i=1}^{p} K_{i}^{*} L^{i}$ and $E\left(e_{t} e_{t}^{\prime}\right)=K^{-1} E\left(\varepsilon_{t} \varepsilon_{t}^{\prime}\right) K^{-1^{\prime}}=K^{-1} \Omega K^{-1^{\prime}}=\Sigma$. Moreover, $\Omega=C C^{\prime}$ is defined such as $E\left(\varepsilon_{t} \varepsilon_{f}^{\prime}\right)=0$ when $t \neq f$. The inverse $\mathrm{C}$ is taken up to construct the matrix $\mathrm{K}$ such as $E\left(e_{t} e_{t}^{\prime}\right)=K^{-1} C C^{\prime} K^{-1^{\prime}}=D C^{-1} C C^{\prime} C^{-1^{\prime}} D^{\prime}=D D^{\prime}$.

The SVAR can be employed to conduct several simulation exercises. Among them we consider a structural impulse response function (IRFs) exercise and a forecast error variance decomposition exercise. The second exercise based on a variance decomposition is to determine the proportion of the variability of the errors in forecasting $X$ vector of variables at time $t+s$ based on the information available at time $\mathrm{t}$ that is due to the variability in the structural shocks $\varepsilon_{t}$ between times $t$ and $t+s$. To do so, a structural decomposition is used to construct forecast errors and impute the proportion of variance for variable $i$ due to shock $j$ at time $t+s$. In general, the recursive causal structure involves restrictions about the contemporaneous relationships among the variables. Such ordering may considerably influence the results. A sensitivity analysis is required to disentangle the potential influence of the chosen ordering and check the robustness of the results.

To proceed in the analysis we need to design a concrete approach to estimate the full model based on eight variables. The variables are taken in log-changes and a constant is added to the model. The full vector of endogenous variables is:

$$
X_{t}=\left[\Delta Y_{t}, \Delta D_{t}, \Delta C P I_{t}, \Delta R P P_{t}, \Delta M_{t}, \Delta C R P_{t}, \Delta C O M_{t}, I N T_{t}\right]^{\prime}
$$


Specifically it includes real output $\left(\Delta Y_{t}\right)$, public debt growth $\left(\Delta D_{t}\right)$, consumer price inflation $\left(\triangle C P I_{t}\right)$, house price dynamics $\left(\triangle R P P_{t}\right)$, money growth $\left(\Delta M_{t}\right)$, private credit growth $\left(\triangle C R P_{t}\right)$, commodity inflation $\left(\triangle C O M_{t}\right)$ and short-term interest rate $\left(I N T_{t}\right)$.

To a certain extent the set of variables included in $X_{t}$ is similar to Sousa and Zaghini (2007) and Belke et al. (2010a). Consequently we refer these two studies to define the identification scheme. Considering equations 4 and 5 , the residuals $\varepsilon_{t}$ are linked to the structural innovations $e_{t}$ by the non-recursive structure $K e_{t}=\varepsilon_{t}$ :

$$
\left[\begin{array}{cccccccc}
1 & 0 & 0 & 0 & 0 & 0 & 0 & 0 \\
k_{21} & 1 & 0 & 0 & 0 & 0 & 0 & 0 \\
k_{31} & k_{32} & 1 & 0 & 0 & 0 & 0 & 0 \\
k_{41} & k_{42} & k_{43} & 1 & 0 & 0 & 0 & 0 \\
k_{51} & k_{52} & k_{53} & k_{54} & 1 & 0 & 0 & k_{58} \\
k_{61} & 0 & 0 & k_{64} & k_{65} & 1 & 0 & k_{68} \\
k_{71} & k_{72} & k_{73} & k_{74} & k_{75} & k_{76} & 1 & 0 \\
k_{81} & k_{82} & k_{83} & k_{84} & k_{85} & k_{86} & k_{87} & 1
\end{array}\right]\left[\begin{array}{l}
e_{t}^{G D P} \\
e_{t}^{D} \\
e_{t}^{C P I} \\
e_{t}^{R P P} \\
e_{t}^{M} \\
e_{t}^{C R P} \\
e_{t}^{C O M} \\
e_{t}^{I N T}
\end{array}\right]=\left[\begin{array}{l}
\varepsilon_{t}^{G D P} \\
\varepsilon_{t}^{D} \\
\varepsilon_{t}^{C P I} \\
\varepsilon_{t}^{R P P} \\
\varepsilon_{t}^{M} \\
\varepsilon_{t}^{C R P} \\
\varepsilon_{t}^{C O M} \\
\varepsilon_{t}^{I N T}
\end{array}\right]
$$

